\title{
Topotactic Growth of Edge-Terminated MoS2 from MoO2 Nanocrystals
}

Dahl-Petersen, Christian; Sari, Manuel; Brorson, Michael; Moses, Poul Georg; Rossmeisl, Jan; Lauritsen, Jeppe Vang; Helveg, Stig

\section{Published in:}

A C S Nano

Link to article, DOI:

10.1021/acsnano.8b00125

Publication date:

2018

Document Version

Peer reviewed version

Link back to DTU Orbit

Citation (APA):

Dahl-Petersen, C., Sari, M., Brorson, M., Moses, P. G., Rossmeisl, J., Lauritsen, J. V., \& Helveg, S. (2018). Topotactic Growth of Edge-Terminated $\mathrm{MoS}_{2}$ from $\mathrm{MoO}_{2}$ Nanocrystals. A C S Nano, 12(6), 5351-5358. https://doi.org/10.1021/acsnano.8b00125

\section{General rights}

Copyright and moral rights for the publications made accessible in the public portal are retained by the authors and/or other copyright owners and it is a condition of accessing publications that users recognise and abide by the legal requirements associated with these rights.

- Users may download and print one copy of any publication from the public portal for the purpose of private study or research.

- You may not further distribute the material or use it for any profit-making activity or commercial gain

- You may freely distribute the URL identifying the publication in the public portal 


\section{Article}

\section{Topotactic Growth of Edge-Terminated MoS from MoO Nanocrystals}

Christian Dahl-Petersen, Manuel Sari\#, Michael Brorson, Poul

Georg Moses, Jan Rossmeisl, Jeppe V. Lauritsen, and Stig Helveg

ACS Nano, Just Accepted Manuscript • DOI: 10.1021/acsnano.8b00125 • Publication Date (Web): 16 May 2018

Downloaded from http://pubs.acs.org on May 22, 2018

\section{Just Accepted}

"Just Accepted" manuscripts have been peer-reviewed and accepted for publication. They are posted online prior to technical editing, formatting for publication and author proofing. The American Chemical Society provides "Just Accepted" as a service to the research community to expedite the dissemination of scientific material as soon as possible after acceptance. "Just Accepted" manuscripts appear in full in PDF format accompanied by an HTML abstract. "Just Accepted" manuscripts have been fully peer reviewed, but should not be considered the official version of record. They are citable by the Digital Object Identifier (DOI®). "Just Accepted" is an optional service offered to authors. Therefore, the "Just Accepted" Web site may not include all articles that will be published in the journal. After a manuscript is technically edited and formatted, it will be removed from the "Just Accepted" Web site and published as an ASAP article. Note that technical editing may introduce minor changes to the manuscript text and/or graphics which could affect content, and all legal disclaimers and ethical guidelines that apply to the journal pertain. ACS cannot be held responsible for errors or consequences arising from the use of information contained in these "Just Accepted" manuscripts. 


\title{
Topotactic Growth of Edge-Terminated $\mathrm{MoS}_{2}$ from
}

\section{$\mathrm{MoO}_{2}$ Nanocrystals}

\author{
Christian Dahl-Petersen ${ }^{1,2}$, Manuel Saric ${ }^{3}$, Michael Brorson ${ }^{1}$, Poul Georg Moses ${ }^{1}$, Jan \\ Rossmeisl $^{4}$, Jeppe Vang Lauritsen ${ }^{2}$, Stig Helveg ${ }^{1, *}$ \\ ${ }^{1}$ Haldor Topsoe A/S, Haldor Topsøes Allé 1, DK-2800 Kgs. Lyngby, Denmark \\ ${ }^{2}$ Interdisciplinary Nanoscience Center (iNANO), Aarhus University, Gustav Wieds Vej 14, DK- \\ 8000 Aarhus C, Denmark \\ ${ }^{3}$ Technical University of Denmark, Department of Physics, DK-2800 Kgs. Lyngby, Denmark \\ ${ }^{4}$ University of Copenhagen, Nano-Science Center, Department of Chemistry, Universitetsparken \\ 5, DK-2100 Copenhagen, Denmark \\ *Address correspondence to sth@topsoe.com
}

Keywords. Topotaxy, growth mechanism, $\mathrm{MoS}_{2}$, edge-termination, in situ transmission electron microscopy, density functional theory

\begin{abstract}
.
Layered transition metal dichalcogenides have distinct physicochemical properties at their edgeterminations. The production of an abundant density of edge structures is, however, impeded by
\end{abstract}


the excess surface energy of edges compared to basal planes and would benefit from insight into the atomic growth mechanisms. Here, we show that edge-terminated $\mathrm{MoS}_{2}$ nanostructures can form during sulfidation of $\mathrm{MoO}_{2}$ nanocrystals by using in situ transmission electron microscopy (TEM). Time-resolved TEM image series reveal that the $\mathrm{MoO}_{2}$ surface can sulfide by inward progression of $\mathrm{MoO}_{2}(20-2): \mathrm{MoS}_{2}(002)$ interfaces resulting in upright-oriented and edgeexposing $\mathrm{MoS}_{2}$ sheets. This topotactic growth is rationalized in interplay with density functional theory calculations by successive O-S exchange and Mo sublattice restructuring steps. The analysis shows that $e-\mathrm{MoS}_{2}$ formation is energetically favorable at $\mathrm{MoO}_{2}(110)$ surfaces and provides a necessary requirement for the propensity of a specific $\mathrm{MoO}_{2}$ surface termination to form edge-terminated $\mathrm{MoS}_{2}$. Thus, the present findings should benefit the rational development of transition metal dichalcogenide nanomaterials with abundant edge-terminations.

Progress in the synthesis of layered transition metal dichalcogenides (TMDCs) has led to a variety of nanoscale structures including fullerenes, tubes/wires and platelets, each with distinct physicochemical properties. ${ }^{1}$ These TMDC structures are derived from layers of hexagonally arranged transition metal atoms (e.g. Mo and $\mathrm{W})$ in which each metal atom is coordinated by six chalcogenide atoms usually in a trigonal prismatic geometry. Such TMDC sheets are terminated by extended basal planes with a regular atomic arrangement and by atomically thin edges. Due to the reduced atomic coordination, the edges expose structures that markedly differ from those of the basal plane and, in turn, offer distinct electronic, ${ }^{2,3}$ optical, ${ }^{4}$ magnetic $^{5}$ and chemical $^{6,7}$ properties. In particular, the edges of $\mathrm{MoS}_{2}$ sheets have long received interest as catalysts for mineral oil refining, ${ }^{8,9}$ hydrogen evolution, ${ }^{10,11} \mathrm{CO}_{2}$ reduction ${ }^{12}$ and photo-oxidation ${ }^{13}$ reactions, whereas the unperturbed $\mathrm{MoS}_{2}$ basal plane is regarded as essentially inert. These catalytic 
processes would therefore benefit from edges that are more abundantly available. In addition, exposed edges are also beneficial for reducing steric hindrance in adsorption of e.g. heavy sulfurcontaining organic compounds, which is a prime target in improving catalysts for oil refining processes. $^{14}$

The availability of edge sites depends on the size, shape and orientation of the TMDC sheets. As the edge terminations are associated with a considerably higher surface energy than the basal plane, the formation of edge sites is suppressed compared to the growth of basal planes. Hence, TMDC sheets are expected to form with extended basal plane exposed to the surroundings and oriented parallel with a supporting surface. In contrast, the sulfidation or thermolysis of molybdenum precursors dispersed on a support material have empirically been found to also produce upright-oriented and thereby edge-exposing $\mathrm{MoS}_{2}$ sheets. ${ }^{12,13,15-26}$ Common for the majority of these edge-favoring synthesis procedures is the employment of a dense molybdenum precursor in the form of nanoparticles or thin films. ${ }^{12,13,15,18-23}$ The appearance of the upright orientation has been attributed to a strong bonding of the $\mathrm{MoS}_{2}$ edge to the supporting material to counteract the thermodynamic drive towards a parallel orientation. ${ }^{16,27,28}$ However, an elaborate understanding of the atomic mechanisms governing the formation of the edge-terminated $\mathrm{MoS}_{2}$ is still lacking and bottom-up strategies have therefore not been available for synthesizing edge-terminated materials with superior catalytic and other functionalities.

With recent advances in transmission electron microscopy (TEM), dynamic transformations of solid materials can now be monitored in situ at high spatial resolution during exposure to reactive gas or liquid environments. By acquiring time-lapsed series of TEM images, it has become possible to gain insight into the mechanisms and kinetics involved in the formation 
of different types of nanometer-sized structures. ${ }^{29-31}$ Here, we employ this TEM approach to monitor the growth of $\mathrm{MoS}_{2}$ nanostructures from molybdenum(IV) oxide $\left(\mathrm{MoO}_{2}\right)$ nanocrystals in situ during exposure to a reactive $\mathrm{H}_{2} \mathrm{~S} / \mathrm{H}_{2}$ atmosphere. The time-resolved TEM image series reveal that the oxide nanocrystal surfaces can form domains of upright-oriented $\mathrm{MoS}_{2}$ sheets by the progression of the $\mathrm{MoO}_{2}(20-2): \mathrm{MoS}_{2}(002)$ interface from the $\mathrm{MoO}_{2}$ surface toward its bulk, in addition to domains of parallel-oriented $\mathrm{MoS}_{2}$ sheets (Figure 1a). This topotactical reaction is explained in interplay with density functional theory (DFT) modelling by repeated steps of O-S exchange and Mo sublattice restructuring. Specifically, these reaction steps exhibit a marked dependency of the $\mathrm{MoO}_{2}$ surface structure in the way that energetically favors formation of edgeterminated $\mathrm{MoS}_{2}$ sheets at the $\mathrm{MoO}_{2}(110)$ surface. The implication of these findings is therefore that (110)-terminated $\mathrm{MoO}_{2}$ precursors can produce abundantly available $\mathrm{MoS}_{2}$ edge sites and that the reaction steps offer descriptors for surface topotaxy, which should, in general, facilitate the design of TMDC nanomaterials with superior edge functionalities.

\section{Results/Discussion}

The electron microscope experiments used $\mathrm{MoO}_{2}$ nanoparticles as precursor because (1) previous studies suggested that molybdenum-dense precursors favor formation of uprightoriented $\mathrm{MoS}_{2}$ sheets, (2) nanoparticles enable surface-profile imaging by electron microscopy and (3) reduced $\mathrm{MoO}_{3}$, such as $\mathrm{MoO}_{2}$ and $\mathrm{MoO}_{3-\mathrm{x}}$, has been considered as intermediate in sulfidation by $\mathrm{H}_{2} \mathrm{~S} / \mathrm{H}_{2}$ into inorganic fullerene structures. ${ }^{32,33}$ The molybdenum(IV) oxide precursor was formed by heating ammonium heptamolybdate tetrahydrate $\left(\left(\mathrm{NH}_{4}\right)_{6}\left[\mathrm{Mo}_{7} \mathrm{O}_{24}\right] \cdot 4 \mathrm{H}_{2} \mathrm{O}\right)$ to $450^{\circ} \mathrm{C}$ at the base vacuum of ca. $5 \times 10^{-6}$ mbar (Methods). The procedure resulted in nanoparticles with projected diameters in the range of 5 to $20 \mathrm{~nm}$ and with 
the monoclinic $\mathrm{MoO}_{2}$ crystal structure ${ }^{34,35}$ (Figures $\mathrm{S} 1$ and $\mathrm{S} 2$ in the Supporting Information). The $\mathrm{MoO}_{2}$ nanocrystals exposed predominantly low-indexed facets such as e.g. (100), (010) and (110) (Figure $\mathrm{S} 2$ in the Supporting Information). Subsequently, the as-prepared $\mathrm{MoO}_{2}$ nanocrystals were exposed to a gas mixture of $10 \% \mathrm{H}_{2} \mathrm{~S}$ in $\mathrm{H}_{2}$ at a total pressure of 1 mbar and heated to a nominal temperature of $250-300^{\circ} \mathrm{C}$ for $240-300$ min inside the electron microscope (Methods). Such low temperatures have previously been associated with the synthesis of uprightoriented $\mathrm{MoS}_{2}$ sheets. ${ }^{16,17}$ During the present treatment, structures emerged that are attributed to molybdenum sulfide because they were absent in similar experiments without $\mathrm{H}_{2} \mathrm{~S}$ in the reaction gas (Figure S3 in the Supporting Information). The molybdenum sulfide structures appeared with two distinctly different orientations relative to the surface of the $\mathrm{MoO}_{2}$ nanocrystals.

The first structure, denoted $e-\mathrm{MoS}_{2}$, represents our main finding and surprisingly consists of sheets oriented upright with respect to the projected nanocrystal surface (Figure 1a). The sheets represent lattice fringes with spacing of ca. $0.62 \mathrm{~nm}$, corresponding to the $\mathrm{MoS}_{2}(002)$ lattice planes (Figure 1b). Domains of $e-\mathrm{MoS}_{2}$ extend from the projected periphery towards the bulk of the nanocrystal and typically consist of 3-8 $\mathrm{MoS}_{2}$ sheets with length of $1-5 \mathrm{~nm}$ (Figure $1 \mathrm{~b}$ and Figures S4-S6 in the Supporting Information). Thus, $e-\mathrm{MoS}_{2}$ exposes predominantly edge sites to the surroundings. Due to the projection geometry, it is possible that the $e-\mathrm{MoS}_{2}$ only partly covers the corresponding surface termination oriented along the electron beam direction (Figure 2) and that the remaining $\mathrm{MoO}_{\mathrm{x}}$ sites eventually sulfide to cover the nanocrystal surface by $p-\mathrm{MoS}_{2}$. Moreover, the anisotropy of $\mathrm{MoS}_{2}$ sheets implies that the corresponding TEM image contrast depends strongly on their orientation. $\mathrm{MoS}_{2}$ sheets oriented with their (002) basal plane along the electron beam direction obtain strong phase contrast in high-resolution TEM images, whereas $\mathrm{MoS}_{2}$ sheets having the (002) planes tilted more than ca. $9^{\circ}$ off the electron beam 
direction appear with a markedly diminished contrast due to the reduced number of atoms contributing to the projected electrostatic potential. ${ }^{36,37}$ Therefore, domains of $e-\mathrm{MoS}_{2}$ may be present in other parts of the $\mathrm{MoO}_{2}$ nanocrystal and remain unresolved in the TEM images due to their orientation. It is therefore not surprising that the $e-\mathrm{MoS}_{2}$ structure was observed in only about $13 \%$ of all nanocrystals (Note in the Supporting Information). However, the low abundance of $e-\mathrm{MoS}_{2}$ could also reflect that only certain surface facets of the parent $\mathrm{MoO}_{2}$ nanocrystal promote growth of the edge-terminated $\mathrm{MoS}_{2}$.

The second structure, denoted $p-\mathrm{MoS}_{2}$, consists of sheets contouring the surface of most of the $\mathrm{MoO}_{2}$ nanocrystals (Figure 1a, note in the Supporting Information). Occasionally, these sheets stack with an interlayer spacing of ca. $0.63 \mathrm{~nm}$, corresponding to the $\mathrm{MoS}_{2}(002)$ lattice planes, and reveal internal lattice fringes with spacing of $0.27 \mathrm{~nm}$, corresponding to (100) lattice planes (Figure $1 \mathrm{~b}$ and $1 \mathrm{c}$ ). The $p-\mathrm{MoS}_{2}$ sheets extend along the projected $\mathrm{MoO}_{2}$ surface parallel to the electron beam. In addition, the sheets are likely also contouring those parts of the $\mathrm{MoO}_{2}$ nanocrystal surface that is not parallel with the electron beam direction (within $\sim \pm 9^{\circ}$ ) and $p$ $\mathrm{MoS}_{2}$ therefore remain undetectable in such regions of the TEM images due to their orientation and overlaid contrast from the projected bulk $\mathrm{MoO}_{2}$ nanocrystal. Thus, the $p-\mathrm{MoS}_{2}$ structure consists of $\mathrm{MoS}_{2}$ sheets that are confined to the surface region of the $\mathrm{MoO}_{2}$ nanocrystal and expose predominantly the $\operatorname{MoS}_{2}(002)$ basal plane, similarly to previous findings for fullerene $\mathrm{MoS}_{2}$ structures. $^{32,33,38}$

To address the growth mode of the edge-terminated $\mathrm{MoS}_{2}, e-\mathrm{MoS}_{2}$, an analysis is first presented of time-resolved series of TEM images that were acquired of individual $\mathrm{MoO}_{2}$ nanocrystals as the sulfidation reaction progressed. Figure 2 shows an image sequence (extracted from Video S1 in the Supporting Information) revealing the dynamic transformation of the 
surface on a $\mathrm{MoO}_{2}$ nanocrystal during sulfidation. The images show that the $\mathrm{MoS}_{2}$ sheets nucleate directly in the exposed $\mathrm{MoO}_{2}$ surface without any additional surface layers. Adjacent $\mathrm{MoS}_{2}$ sheets form simultaneously and establish a domain of $e-\mathrm{MoS}_{2}$. Subsequently, the $\mathrm{MoS}_{2}$ sheets grow in length from the original surface toward the bulk of the $\mathrm{MoO}_{2}$ nanocrystal, reaching a final length of ca. $2.8 \mathrm{~nm}$. Figure S7 in the Supporting Information shows that the $\mathrm{MoS}_{2}$ sheets grow initially fast and that the growth stagnates at longer sulfidation times. The decay of the growth rate may be due to the slower mass transport through the bulk of the nanoparticle. Similar dynamic behavior is revealed in the formation of shorter $e-\mathrm{MoS}_{2}$ structures albeit at a corresponding lower signal-to-noise ratio (Figure S5 in the Supporting Information). On average, $e-\mathrm{MoS}_{2}$ sheets observed in situ grew to a final average projected length of $1.7 \mathrm{~nm}$ (with a standard deviation of $0.6 \mathrm{~nm}$ ) and sheets observed post mortem had grown to an average projected length of $1.8 \mathrm{~nm}$ (with a standard deviation of $0.7 \mathrm{~nm}$ ) (Figure S8 in the Supporting Information). This conformity demonstrates that alterations of the growth process induced by the electron illumination were insignificant with the applied low dose-rate imaging protocol and that the observed $\mathrm{MoS}_{2}$ formation is inherent to the sulfidation reaction as such (Methods). Thus, the time-resolved observations indicate that growth of $e-\mathrm{MoS}_{2}$ proceeded by an $\mathrm{O}-\mathrm{S}$ exchange reaction and by an inward progression of the $\mathrm{MoO}_{2}: \mathrm{MoS}_{2}$ interface from the surface of the $\mathrm{MoO}_{2}$ nanocrystal upon continued exposure to the sulfur-rich gas.

To address the relation between the $e-\mathrm{MoS}_{2}$ and $\mathrm{MoO}_{2}$ host nanocrystal structures, their interface is examined at the atomic-scale. Figure 3 shows a close-up TEM image of the interface, which reveals a threefold periodicity with three $\mathrm{MoO}_{2}(20-2)$ lattice planes matching one single $\mathrm{MoS}_{2}(002)$ lattice plane. The lattice matching at the interface influenced the $\mathrm{MoS}_{2}$ interlayer spacing in such a way that the spacing varied with the distance from the $\mathrm{MoO}_{2}: \mathrm{MoS}_{2}$ interface to 
the nanocrystal surface. Specifically, the $\mathrm{MoS}_{2}(002)$ lattice spacing was larger closer to the interface, corresponding to $3 \mathrm{a}_{\mathrm{MoO} 2[20-2]}=0.73 \mathrm{~nm}$, and smaller near the nanocrystal surface, corresponding to $\mathrm{a}_{\mathrm{MoS} 2[002]}=0.62 \mathrm{~nm}$ (Figure 3). Consistently, shorter $e-\mathrm{MoS}_{2}$ slabs were separated by ca. $0.73 \mathrm{~nm}$ (Figures S4 and S6 in the Supporting Information). The larger $\mathrm{MoS}_{2}(002)$ lattice spacing near the interface constitutes a geometric strain of $+17 \%$, which is energetically feasible due to the weak van der Waals interaction between the $\mathrm{MoS}_{2}$ sheets. A similar analysis of the crystal lattice planes in high-resolution TEM images of nine additional $\mathrm{MoO}_{2}$ nanocrystals also characterized the interface as $\mathrm{MoO}_{2}(20-2): \mathrm{MoS}_{2}(002)$ (Figure S4 in the Supporting Information). This interfacial relation of the two crystal lattices shows that the $e$ $\mathrm{MoS}_{2}$ sheets formed as the result of a topotactic transformation of the $\mathrm{MoO}_{2}$ surface region. ${ }^{39}$ Moreover, as the $\mathrm{MoS}_{2}$ sheets are oriented upright with respect to the projected $\mathrm{MoO}_{2}$ surface, $e$ $\mathrm{MoS}_{2}$ must nucleate at surface facets inclined from the $\mathrm{MoO}_{2}(20-2)$ lattice planes, including the more abundant low-indexed surface terminations, such as (110), (010) and (100).

Furthermore, the conversion of $\mathrm{MoO}_{2}$ into $\mathrm{MoS}_{2}$ by anion exchange also entails a restructuring of the Mo sublattice due to different $\mathrm{Mo}$ atom densities. $\mathrm{MoO}_{2}$ is a monoclinic structure with a density of $30.4 \mathrm{Mo}$ atoms $/ \mathrm{nm}^{3}$, and $\mathrm{MoS}_{2}$ is a hexagonal structure with a density of $18.8 \mathrm{Mo}$ atoms $/ \mathrm{nm}^{3}$. The corresponding volume expansion of $62 \%$ per Mo atom implies that Mo atoms were expelled from the bulk $\mathrm{MoO}_{2}$ during formation of $e-\mathrm{MoS}_{2}$. These Mo atoms possibly contributed to $p-\mathrm{MoS}_{2}$, because $p-\mathrm{MoS}_{2}$ and $e-\mathrm{MoS}_{2}$ formed simultaneously (Figure 2) and $p-\mathrm{MoS}_{2}$ formed at the exterior surface of the $\mathrm{MoO}_{2}$ nanocrystals, causing an apparent increase in the projected size of the nanocrystals (Figure S9 in the Supporting Information).

The present observations of topotactic growth of edge-terminated $\mathrm{MoS}_{2}$ sheets from $\mathrm{MoO}_{2}$ can be rationalized by the atomistic mechanism proposed in Figure 4 . The consistency of 
this mechanism is examined by means of DFT calculations, combined with a thermodynamic extrapolation to the present sulfidation conditions (Methods). First, the conversion of bulk $\mathrm{MoO}_{2}$ to $\mathrm{MoS}_{2}$ is addressed by the reaction:

$$
\mathrm{MoO}_{2}(\mathrm{~s})+2 \mathrm{H}_{2} \mathrm{~S}(\mathrm{~g}) \rightarrow \mathrm{MoS}_{2}(\mathrm{~s})+2 \mathrm{H}_{2} \mathrm{O}(\mathrm{g})
$$

For this reaction, a calculation shows a Gibbs free energy change of $-1.00 \mathrm{eV}$, corresponding to an average gain of $-0.50 \mathrm{eV} / \mathrm{S}$ atom, with $0.9 \mathrm{mbar}_{2}$ and $0.1 \mathrm{mbar} \mathrm{H}_{2} \mathrm{~S}$ at $250{ }^{\circ} \mathrm{C}$. The sulfidation described by eq. (1) initiates at the $\mathrm{MoO}_{2}$ surface. ${ }^{40,41}$ The surface sulfidation by $\mathrm{H}_{2} \mathrm{~S}$ is modelled at the low-indexed (110), (010) or (100) facets of $\mathrm{MoO}_{2}$, consistent with the TEM observations. This process is associated with a free energy change of $-0.01 \mathrm{eV} / \mathrm{S}$ atom, -0.29 $\mathrm{eV} / \mathrm{S}$ atom and $+0.09 \mathrm{eV} / \mathrm{S}$ atom for the $\mathrm{MoO}_{2}(110),(010)$ and (100) surfaces, respectively, at the same conditions. Thus, only the (110) and (010) surface terminations tend to sulfide (Figure S10 in the Supporting Information), whereas the (100) surface remains oxidic under the present reaction conditions.

Following the initial sulfidation, the $\mathrm{MoO}_{2}$ surface is envisioned to develop by successive steps of Mo sublattice reconstruction and O-S exchange to accommodate the upright oriented $\mathrm{MoS}_{2}$ sheets. At the sulfided $\mathrm{MoO}_{2}(110)$ surface, every second topmost [-11-1]-row contains half the number of Mo atoms (row 1 and 3 in Figure 4a) compared to the [-11-1]-rows in the bulk $\mathrm{MoO}_{2}$ structure (row 4 and 5 in Figure 4a). A stepwise displacement of these topmost [-11-1]rows toward each other, by $1 \mathrm{a}_{[20-2]}$ as outlined for row $1(\mathrm{a} \rightarrow \mathrm{b}$ in Figure 4$)$ and row $3(\mathrm{~b} \rightarrow \mathrm{c}$ in Figure 4), results in a sulfided row of Mo atoms with a density similar to $\mathrm{MoS}_{2}[100]$ (note in the Supporting Information). Moreover, the repetition of the displacements along the $\mathrm{MoO}_{2}$ surface develops a threefold periodicity of $\mathrm{MoO}_{2}(20-2): \mathrm{MoS}_{2}(002)$ interface, in agreement with the TEM images. The [-11-1]-row displacements uncover underlying oxide [-11-1]-rows (row 2, 4 and 5 
in Figure 4) comparable to the pristine oxide surface. As the exposure to the sulfiding environment is continuous in the experiments, these oxide rows likewise undergo O-S exchange as well. A two-row high $\mathrm{MoS}_{2}$ sheet therefore emerges extending one row in and out from the initial surface (row $1+3$ and 2 in Figure 4c). Moreover, the deeper-lying $\mathrm{MoO}_{2}$ [-11-1]-rows also partly sulfide upon exposure to the reaction environment (row 4 and 5), and these rows may subsequently transform in a similar way as the outermost rows (row 1 and 3). That is, half of the sulfided Mo atoms in the [-11-1]-rows (row 4 and 5) are displaced into an additional sheet that extends the $e-\mathrm{MoS}_{2}$ sheet outwards. The remaining half-filled Mo [-11-1]-rows (row 4 and 5) mimic the initial state of the sulfided surface (Figure 4a) and therefore undergo the same transformations, resulting in a four-row $e-\mathrm{MoS}_{2}$ sheet (Figure 4d). As a result, the mechanism outlined in Figure 4 a-d becomes cyclic and, in turn, develops an $e-\mathrm{MoS}_{2}$ structure with a $\mathrm{MoO}_{2}(20-2): \mathrm{MoS}_{2}(002)$ interface and a threefold periodicity, consistent with the experimental observations. To corroborate this mechanism, the O-S exchange and Mo [-11-1]-row displacement steps were examined by DFT calculations to evaluate the Gibbs free energy for each state (Methods). Figure 4e shows a successive lowering of the Gibbs free energy per unit cell as the sulfidation reaction progressed, demonstrating that the proposed mechanism for the topotactic growth of $e-\mathrm{MoS}_{2}$ at the $\mathrm{MoO}_{2}(110)$ surface is plausible.

The mechanism in Figure 4 implies that the $e-\mathrm{MoS}_{2}$ sheets grow to the same extent inward and outward from the original $\mathrm{MoO}_{2}$ surface. In contrast, the $\mathrm{MoS}_{2}$ sheets are observed to progress mainly inward and only modestly outward from the original $\mathrm{MoO}_{2}$ surface in the experiment (Figure 2). The asymmetric growth of the $e-\mathrm{MoS}_{2}$ sheets possibly occurs under the experimental conditions, because the Mo atoms expelled from the $\mathrm{MoO}_{2}$ bulk are free to migrate to sites on the $\mathrm{MoO}_{2}$ surface where incorporation into $p-\mathrm{MoS}_{2}$ can occur. In contrast, in the DFT 
modelling the same Mo atoms are added as an outward extension of the $\mathrm{MoS}_{2}$ layer, due to the geometrical constraint of the employed unit cell. The difference may reflect that, in the experimental situation, the outward growth is kinetically limited or the emergence of the basal plane of $p-\mathrm{MoS}_{2}$ is energetically favored over $e-\mathrm{MoS}_{2}$ sheets protruding outward from the original the $\mathrm{MoO}_{2}$ surface.

To address the surface dependency of the topotactic reaction, the sulfidation mechanism is compared on the $\mathrm{MoO}_{2}(110)$ and (010) surfaces (Figure 4 and Figure S11 in the Supporting Information). For both surfaces, the energy gain upon sulfidation is lower than the limit set by equation (1) for growth of bulk $\mathrm{MoS}_{2}$ from $\mathrm{MoO}_{2}$ (0.50 eV/S atom). Specifically, for the $\mathrm{MoO}_{2}$ (110) and (010) surface, the corresponding Gibbs free energy difference from the surface to bulk sulfidation is $-0.49 \mathrm{eV} / \mathrm{S}$-atom $(-0.50 \mathrm{eV} / \mathrm{S}$ atom minus $-0.01 \mathrm{eV} / \mathrm{S}$ atom) and $-0.21 \mathrm{eV} / \mathrm{S}$ atom ($0.50 \mathrm{eV} / \mathrm{S}$ atom minus $-0.29 \mathrm{eV} / \mathrm{S}$ atom), respectively, under the present conditions. Thus, $\mathrm{S}$ atoms are less stable on the (110) than the (010) surface with respect to the $e-\mathrm{MoS}_{2}$ structure. In addition, the Mo sublattice restructuring also exhibits a surface-dependency. Whereas displacement of the [-11-1] rows is spontaneous on the $\mathrm{MoO}_{2}(110)$ surface $(\mathrm{a} \rightarrow \mathrm{b}$ in Figure $4 \mathrm{e})$, the displacement of [101]-rows on the $\mathrm{MoO}_{2}(010)$ surface into a one-row high $\mathrm{MoS}_{2}$ sheet $(\mathrm{a} \rightarrow$ b in Figure S11 in the Supporting Information) is associated with a Gibbs free energy change of $+2.74 \mathrm{eV} /$ unit-cell (Figure 4e). This energy change results from the higher Mo atom density in the (010) surface (note in the Supporting Information) and adds a barrier for restructuring the Mo sublattice that suppresses growth of $e-\mathrm{MoS}_{2}$. Thus, the calculations show that growth of $e-\mathrm{MoS}_{2}$ is favored on $\mathrm{MoO}_{2}(110)$ due to the large energy gain for transferring surface $\mathrm{S}$ atoms into bulk $\mathrm{MoS}_{2}$ and the spontaneous and facile restructuring the Mo sublattice, whereas formation of $e$ - 


\begin{abstract}
$\mathrm{MoS}_{2}$ is hindered on $\mathrm{MoO}_{2}(010)$ due to the smaller energy gain in the $\mathrm{S}$ transfer and the larger barrier for Mo sublattice restructuring.
\end{abstract}

\title{
Conclusion
}

The present study demonstrates the O-S exchange energy and the Mo sublattice reconstruction energy as descriptors for the propensity of a specific $\mathrm{MoO}_{2}$ surface to form $e$ $\mathrm{MoS}_{2}$, and the analysis provides a necessary requirement for a $\mathrm{MoO}_{2}$ surface to facilitate a spontaneous topotactic transformation into edge-terminated $\mathrm{MoS}_{2}$. This insight may help understanding previous reports on oriented nucleation and growth of $\mathrm{MoS}_{2}$ sheets based on the surface properties of the molybdenum oxide precursors. ${ }^{16-18}$ Moreover, the present findings suggest that the $e-\mathrm{MoS}_{2}$ growth is energetically favored at (110) surfaces of a $\mathrm{MoO}_{2}$ nanomaterials under the present growth conditions. In the future, developing shape-selective synthesis procedures of $\mathrm{MoO}_{2}$ nanomaterials with an enhanced abundance of (110) surface terminations therefore seems as one viable route for optimizing the abundance of $e-\mathrm{MoS}_{2}$. The $e$ $\mathrm{MoS}_{2}$ formation could be kinetically limited by adsorption or diffusion processes not considered in the present analysis. Such limitations can be addressed by detailed characterization using oxygen adsorption of the $\mathrm{MoS}_{2}$ edge sites ${ }^{42}$ and a shape-determination of the $\mathrm{MoO}_{2}$ nanomaterial using electron microscopy or X-ray diffraction. ${ }^{43}$ Conceptually, the present descriptors of surface topotaxy may be generally applicable in guiding bottom-up synthesis procedures of TMDC nanomaterials towards enhanced edge-functionalities. 


\section{Methods/Experimental}

Sample preparation and sulfidation. Ammonium heptamolybdate tetrahydrate, $\left(\mathrm{NH}_{4}\right)_{6} \mathrm{Mo}_{7} \mathrm{O}_{24} \cdot 4 \mathrm{H}_{2} \mathrm{O}$ (Merck, 1180336, minimum 99\% nominal purity) was used as molybdenum precursor. The precursor granulate was ground to a fine powder and dispersed in its dry state onto plasma-cleaned Protochips Aduro E-chips or FEI Company NanoEx chips. Precursor particles were approximately 2-5 $\mu \mathrm{m}$ wide and overhung the membrane holes near the center of the chip membrane. Heating of the chips to $450^{\circ} \mathrm{C}$ in the microscope base vacuum transformed the precursor into $\mathrm{MoO}_{2}$ nanoparticles ranging from 5 to $20 \mathrm{~nm}$ in width. For the Aduro E-chips, $\mathrm{MoO}_{2}$ nanoparticles protruding from holes in the second innermost quadrant of $7 \times 7$ hole arrangement were examined in the electron microscope to ensure temperature uniformity $^{44}$ and to minimize the image contrast contribution from the chip membranes. The NanoEx chips have a uniform temperature across the perforated membrane, ${ }^{45}$ and particles protruding from any hole were imaged by TEM.

To initiate the sulfidation reaction, the temperature of the chip was lowered to $300^{\circ} \mathrm{C}$ or $250^{\circ} \mathrm{C}$, and subsequently a premixed gas with $10 \% \mathrm{H}_{2} \mathrm{~S}$ in $\mathrm{H}_{2}$ (Air Liquide, nominal purity $98 \%$ for $\mathrm{H}_{2} \mathrm{~S}$ and $99.999 \%$ for $\mathrm{H}_{2}$ ) was introduced into the electron microscope at time $=0 \mathrm{~min}$. The gas composition was continuously monitored using a quadrupole mass spectrometer (Balzers Prisma QMS 200) positioned at the microscope second differential pumping step for masses 2, 16, 18, 32, 33 and 34 AMU corresponding to signals from $\mathrm{H}_{2}, \mathrm{O}_{2}, \mathrm{H}_{2} \mathrm{O}, \mathrm{S}, \mathrm{HS}$, and $\mathrm{H}_{2} \mathrm{~S}$. This showed that a constant gas composition was obtained after 5 min at constant gas pressure (Figure S12 in the Supporting Information). The ion currents were sampled at a total acquisition time of $11 \mathrm{sec}$. 
Transmission electron microscopy (TEM). The growth of $\mathrm{MoS}_{2}$ was examined by means of a Philips CM300 FEG-ST transmission electron microscope, which is equipped with a differential pumping system and heating stages to enable the exposure of solid specimens to reactive gasses and elevated temperatures. ${ }^{37,46}$ Specifically, this microscope is dedicated to experiments including corrosive sulfur-containing gases. ${ }^{37}$ The microscope was operated at a primary electron energy of $300 \mathrm{keV}$ and with an electron dose-rate of $150 \mathrm{e}^{-/}\left(\AA^{2} \mathrm{~s}\right)$ for in situ observations with $10 \% \mathrm{H}_{2} \mathrm{~S}$ in $\mathrm{H}_{2}$ at 1 mbar total pressure in the sample region and of $200 \mathrm{e}^{-} /\left(\AA^{2} \mathrm{~s}\right)$ for post mortem observations under a high vacuum of better than $5 \times 10^{-6}$ mbar in the sample region. The applied gas environment reduced the electron transmittance by only ca. 3\% relative to vacuum. Therefore, electron doses and dose-rates are quoted with reference to measurements in the evacuated microscope. Moreover, the microscope projection system was set at a magnification corresponding to an effective pixel size ranging from $0.03 \mathrm{~nm}$ to $0.07 \mathrm{~nm}$ of the charged coupled device (CCD) camera (Tietz F114) during TEM image acquisition. These magnification settings are sufficient to resolve the $\mathrm{MoS}_{2}$ (100) lattice planes of spacing $0.27 \mathrm{~nm}$ and the $\mathrm{MoO}_{2}(20-2)$ lattice planes of spacing $0.24 \mathrm{~nm}$, as the shortest lattice spacings. Moreover, imaging was done at focus settings close to the Scherzer defocus value of $\mathrm{f}=-64 \mathrm{~nm}$ to ensure a large contrast information transfer for the $\mathrm{MoS}_{2}(002)$ and (100) lattice planes and the $\mathrm{MoO}_{2}(20-2)$ lattice planes. The CCD illumination time was 0.5 - $1 \mathrm{~s}$ per image.

The experiments were conducted using micro-electro-mechanical heaters as sample support. A part of the experiments employed the Protochips Aduro system, which consists of silicon chips supporting silicon carbide membranes perforated with $7 \times 7$ holes near the center. ${ }^{47}$ Prior to sample loading, chips were exposed to $\mathrm{Ar} / \mathrm{O}_{2}$ plasma for cleaning. In the experiment, sample dispersed on the membranes was heated by resistively passing an electrical current 
through the membrane. The membrane current-temperature characteristic was calibrated using pyrometry at a pressure of $1.3 \times 10^{-2}$ mbar by the manufacturer (Protochips). During gas exposure in the microscope, additional heat dissipation to the gas phase was accounted for by operating the membrane in a constant resistance mode ${ }^{37}$ The other part of the experiments employed the FEI Company NanoEx system, which consists of silicon chips with a silicon nitride membrane perforated with 22 holes near its center and a conductive thin film with four electrodes for resistive heating and on-board temperature sensing. ${ }^{45}$ Prior to sample loading, chips were also exposed to $\mathrm{Ar} / \mathrm{O}_{2}$ plasma for cleaning. The temperature-resistance characteristic of the chips was provided by the manufacturer (FEI Company).

During a sulfidation experiment, 3-4 sample regions were monitored. The regions were located at distances larger than the width of the electron beam, so that the regions were monitored separately. As sulfidation of the sample progressed, each region was imaged every approximately $15 \mathrm{~min}$. and each imaging step lasted for a maximum of $60 \mathrm{~s}$ for positioning, focusing and image acquisition. The total experiment duration was 240-300 min, corresponding to a total of up to 21 electron beam exposures of each region. The maximal total accumulated electron dose incident on a region in the in situ experiments was therefore $189 \times 10^{3} \mathrm{e}^{-} / \AA^{2}$, using an electron dose rate of $150 \mathrm{e}^{-} /\left(\AA^{2} \mathrm{~s}\right)$. At each position and time step, an image series of 5 or 10 sequential images was acquired. These images were post-aligned using cross-correlation and summed to the final displayed images with improved signal-to-noise-ratio. Immediately after an imaging step, the electron beam was moved to the next sample position. This imaging strategy was applied to minimize the total dose rate while maintaining a detectable image signal. ${ }^{48}$ Additional images series were obtained after termination of the sulfidation reaction at positions 
without prior exposure to the electron beam (post mortem). These post mortem images were acquired at a base vacuum below $5 \times 10^{-6}$ mbar and $120^{\circ} \mathrm{C}$.

The magnification of the TEM images was calibrated relative to a standard $\mathrm{Au} / \mathrm{C}$ calibration grid. The images are represented as a direct representation of the summed CCD current outputs in a monochromatic green color scale with only a linear adjustment of the image contrast and brightness.

Image simulation. High-resolution TEM images of $\mathrm{MoO}_{2}$ were simulated using the multi-slice approach as implemented in the MacTempasX software. ${ }^{49}$ To describe the Philips CM300 microscope, the simulations employed an incident electron beam energy of $300 \mathrm{keV}$, spherical aberration coefficient of $\mathrm{C}_{\mathrm{s}}=1.4 \mathrm{~mm}$, a convergence angle of $0.3 \mathrm{mrad}$, a defocus spread of 8.3 $\mathrm{nm}$, an outer objective aperture of $0.14 \mathrm{~nm}$, and a mechanical vibration amplitude in the imaging plane of $0.07 \mathrm{~nm}$. The $\mathrm{MoO}_{2}$ nanoparticles were described by a monoclinic $\mathrm{MoO}_{2}$ crystal structure $^{32}$ belonging to the $\mathrm{P} 2_{1} / \mathrm{c}$ space group.

Theoretical calculations. The GPAW $\mathrm{W}^{50,51}$ density functional theory code was employed in finite difference mode using a grid spacing of $0.18 \AA$ to obtain total energies. The exchange and correlation was described by the revised Perdew-Burke-Ernzerhof (RPBE) functional. All atomic positions in the systems involving $\mathrm{MoO}_{2}$ and $\mathrm{MoS}_{2}$ structures were relaxed until the largest interatomic force was smaller than or equal to $0.05 \mathrm{eV} / \AA$ and the molecules were relaxed to a value less than $0.01 \mathrm{eV} / \AA$. The DFT electronic energies of $\mathrm{H}_{2} \mathrm{~S}$ and $\mathrm{H}_{2} \mathrm{O}$ were corrected with zero-point energies and entropic contributions. The zero-point energy corrections were obtained by performing vibrational analysis calculations in GPAW using the harmonic approximation. ${ }^{52}$ The remaining thermodynamic corrections were obtained from thermochemical tables. ${ }^{53}$ The calculations employed reaction conditions at $250^{\circ} \mathrm{C}$ with 0.1 mbar $\mathrm{H}_{2} \mathrm{~S}$ and $0.9 \mathrm{mbar}_{2}$, 
matching the experimental sulfidation conditions. The calculations used an estimated $\mathrm{H}_{2} \mathrm{O}$ pressure of $10^{-3}$ mbar to reflect an upper limit of the residual gas phase in the electron microscope.

The bulk structure of monoclinic $\mathrm{MoO}_{2}$ was modeled using a unit cell consisting of $4 \mathrm{Mo}$ and $8 \mathrm{O}$ atoms periodic in the $\mathrm{x}, \mathrm{y}$ and $\mathrm{z}$ directions, respectively. Bulk $\mathrm{MoS}_{2}$ was modeled as infinite layers periodic in the $\mathrm{x}$ [110] and $\mathrm{y}$ [1-10] directions, separated by vacuum in the $\mathrm{z}$ [002] direction and with $2 \mathrm{Mo}$ and $4 \mathrm{~S}$ atoms in the unit cell. The Brillouin zone was sampled with 8,8,8 k-points in the $\mathrm{x}, \mathrm{y}$ and $\mathrm{z}$ directions, respectively, both for bulk $\mathrm{MoO}_{2}$ and $\mathrm{MoS}_{2}$. The surfaces were modeled as symmetric layers of six (010) or (110) $\mathrm{MoO}_{2}$ layers periodic in the $\mathrm{x}$ [20-2] and $\mathrm{y}[101]$ or [-11-1] lattice directions and separated by $13 \AA$ of vacuum in the $\mathrm{z}[010]$ or [110] direction to prevent the surfaces from interacting due to the periodic boundary conditions. The DFT calculations of the $\mathrm{MoO}_{2}$ surface employed a periodicity of 4 along the [20-2] direction. Importantly, the unit cell dimension of $4 \mathrm{x} \mathrm{a}_{[20-2]}$ is longer than the observed periodicity of $3 \mathrm{xa}_{[20-2]}$ at the $\mathrm{MoO}_{2}: \mathrm{MoS}_{2}$ interface (Figure 3). The longer periodicity employed in the DFT calculations ensured that periodic boundaries could be invoked and kept the computational time low. Moreover, the periodicity in the DFT calculations is a pure geometric effect, because identical exchange and Mo sublattice restructuring occurs locally in the larger cell and the extra surface energy is canceled out by the reference (Figure 4a). Therefore, the present calculations still capture the energetics in the transformation of three $\mathrm{MoO}_{2}$ planes into one $\mathrm{MoS}_{2}$ sheet.

The Brillouin zone of the $\mathrm{MoO}_{2}$ for the (010) and (110) surface slabs were sampled with 4, 4, 1 k-points in the $\mathrm{x}$ [20-2], $\mathrm{y}$ [101] or [-11-1] and $\mathrm{z}$ [010] or [110] directions, respectively. The energies for the surface sulfidation were obtained by replacing all directly gas exposed $\mathrm{O}$ atoms with $\mathrm{S}$ atoms and using gas phase $\mathrm{H}_{2} \mathrm{O}$ and $\mathrm{H}_{2} \mathrm{~S}$ as references. For the calculations 
regarding the reconstructive growth mechanism of $\mathrm{MoS}_{2}$ the unit cell had to be repeated once in the $\mathrm{x}$ direction for the $\mathrm{MoO}_{2}(010)$ and in the $\mathrm{y}$ direction for the $\mathrm{MoO}_{2}(110)$ surface in order to prevent the formed $\mathrm{MoS}_{2}$ sheets from overlapping. The Brillouin zone was thus sampled with 4, 2, 1 k-points for the (010) system and 2, 4, 1 k-points for the (110) system in the $\mathrm{x}$ [20-2], $\mathrm{y}$ [101] or [-11-1] and z [010] or [110] directions, respectively. Details regarding calculation of the data points in Figure 4e are given in Supplementary methods in the Supporting Information.

\section{Acknowledgment.}

The work was performed at the electron microscope facility at Haldor Topsoe A/S. CDP acknowledges financial support from Innovation Fund Denmark (grant Cat-C), and MS acknowledges financial support from Innovation Fund Denmark (grant HYDECAT). The authors acknowledge S. Ullmann (Haldor Topsoe A/S), S. Kegnæs (Technical University of Denmark (DTU)) and Q. Ramasse (SuperSTEM, UK) for fruitful discussions.

\section{Supporting Information.}

Note, Supplementary methods and Figures S1-S12 (PDF)

Video $\mathrm{S} 1$ accompanies Figure 2 and shows a $\mathrm{MoO}_{2}$ nanocrystal during the exposure to 1 mbar of $10 \% \mathrm{H}_{2} \mathrm{~S}$ in $\mathrm{H}_{2}$ at $250^{\circ} \mathrm{C}$. The images are recorded with $15 \mathrm{~min}$ intervals, with the first image equivalent to $45 \mathrm{~min}$ of gas exposure. The movie is displayed with 2 frames per second. Each frame corresponds to an image series of 5 exposures, which are post-aligned using crosscorrelation and summed to improve the image signal-to-noise ratio. description (AVI) 


\section{References}

1 Tenne, R. Inorganic Nanotubes and Fullerene-like Nanoparticles. Nat. Nanotechnol. 2006, 1, 103-111.

2 Xu, H.; Liu, S.; Ding, Z.; Tan, S. J. R.; Yam, K. M.; Bao, Y.; Nai, C. T.; Ng, M.-F.; Lu, J.; Zhang, C Loh, K. P. Oscillating Edge States in One-Dimensional $\mathrm{MoS}_{2}$ Nanowires. Nat. Commun. 2016, 7, 12904.

3 Bollinger, M. V.; Lauritsen, J. V.; Jacobsen, K. W.; Nørskov, J. K.; Helveg, S.; Besenbacher, F. One-Dimensional Metallic Edge States in $\mathrm{MoS}_{2}$. Phys. Rev. Let. 2001, $87,196803$.

$4 \quad$ Yin, X.; Ye, Z.; Chenet, D. A.; Ye, Y.; O’Brien, K.; Hone, J. C.; Zhang, X. Edge Nonlinear Optics on a $\mathrm{MoS}_{2}$ Atomic Monolayer. Science 2014, 344, 488-490.

5 Vojvodic, A.; Hinnemann, B.; Nørskov, J. K. Magnetic Edge States in $\mathrm{MoS}_{2}$ Characterized by Density-Functional Theory. Phys. Rev. B 2009, 80, 125416.

6 Chhowalla, M.; Shin, H. S.; Eda, G.; Li, L.-J.; Loh, K. P.; Zhang, H. The Chemistry of Two-Dimensional Layered Transition Metal Dichalcogenide Nanosheets. Nat. Chem. 2013, 5, 263-275.

7 Deng, D.; Novoselov, K. S.; Fu, Q.; Zheng, N.; Tian, Z.; Bao, X. Catalysis with TwoDimensional Materials and their Heterostructures. Nat. Nanotechnol. 2016, 11, 218-230.

8 Prins, R. Energy-Related Catalysis: Hydrotreating Reactions: Hydrodesulfurization, Hydrodenitrogenation, Hydrodeoxygenation and Hydrodechlorination in Handbook of Heterogeneous Catalysis (eds. Ertl, G., Knözinger, H. \& Weitkamp, J.), Wiley-VCH Verlag GmbH, 2008.

9 Besenbacher, F.; Brorson, M.; Clausen, B.S.; Helveg, S.; Hinnemann, B.; Kibsgaard, J.; Lauritsen, J.V.; Moses, P.G.; Nørskov, J.K.; Topsøe, H. Recent STM, DFT and HAADFSTEM Studies of Sulfide-Based Hydrotreating Catalysts: Insight into Mechanistic, Structural and Particle Size Effects. Catal. Today 2008, 130, 86-96. 
10 Jaramillo, T.F.; Jørgensen, K.P.; Bonde, J.; Nielsen, J.H.; Horch, S.; Chorkendorff, I. dentification of Active Edge Sites for Electrochemical $\mathrm{H}_{2}$ Evolution from $\mathrm{MoS}_{2}$ Nanocatalysts. Science 2007, 317, 100-102.

11 Hou, Y.; Abrams, B. L.; Vesborg, P. C. K.; Björketun, M. E.; Herbst, K.; Bech, L.; Setti, A. M.; Damsgaard, C. D.; Pedersen, T.; Hansen, O.; Rossmeisl, J.; Dahl, S.; Nørskov, J. K.; Chorkendorff, I. Bioinspired Molecular Co-Catalysts Bonded to a Silicon Photocathode for Solar Hydrogen Evolution. Nat. Mater. 2011, 10, 434-438.

12 Asadi, M.; Kumar, B.; Behranginia, A.; Rosen, B. A.; Baskin, A.; Repnin, N.; Pisasale, D.; Phillips, P.; Zhu, W.; Haasch, R.; Klie, R. F.; Král, P.; Abiade, J.; Salehi-Khojin, A. Robust Carbon Dioxide Reduction on Molybdenum Disulphide Edges. Nat Commun. 2014, 5, 4470 .

13 Liu, C.; Kong, D.; Hsu, P.-C.; Yuan, H.; Lee, H.-W.; Liu, Y.; Wang, H.; Wang, S.; Yan, K.; Lin, D.; Maraccini, P. A.; Parker, K. M.; Boehm, A. B.; Cui, Y. Rapid Water Disinfection using Vertically Aligned $\mathrm{MoS}_{2}$ Nanofilms and Visible Light. Nat. Nanotechnol. 2016, 11, 1098-1104.

14 Tuxen, A. K.; Füchtbauer, H. G.; Temel, B.; Hinnemann, B.; Topsøe, H.; Knudsen, K. G.; Besenbacher, F.; Lauritsen, J. V. Atomic-Scale Insight into Adsorption of Sterically Hindered Dibenzothiophenes on $\mathrm{MoS}_{2}$ and Co-Mo-S Hydrotreating Catalysts. J. Catal. 2012, 295, 146-154.

15 Hayden, T. F.; Dumesic, J. A. Studies of the Structure of Molybdenum Oxide and Sulfide Supported on Thin Films of Alumina. J. Catal. 1987, 103, 366-384.

16 Sakashita, Y.; Araki, Y.; Honna, K.; Shimada, H. Orientation and Morphology of Molybdenum Sulfide Catalysts Supported on Titania Particles, Observed by using HighResolution Electron Microscopy. Appl. Catal., A 2000, 197, 247-253.

17 Shimada, H. Morphology and Orientation of $\mathrm{MoS}_{2}$ Clusters on $\mathrm{Al}_{2} \mathrm{O}_{3}$ and $\mathrm{TiO}_{2} \mathrm{Supports}$ and their Effect on Catalytic Performance. Catal. Today 2003, 86, 17-29.

18 Kibsgaard, J.; Chen, Z. B.; Reinecke, B. N.; Jaramillo, T. F. Engineering the Surface Structure of $\mathrm{MoS}_{2}$ to Preferentially Expose Active Edge Sites for Electrocatalysis. Nat. Mater. 2012, 11, 963-969.

19 Kong, D.; Wang, H.; Cha, J. J.; Pasta, M.; Koski, K. J.; Yao, J.; Cui, Y. Synthesis of $\mathrm{MoS}_{2}$ and $\mathrm{MoSe}_{2}$ Films with Vertically Aligned Layers. Nano Lett. 2013, 13, 1341-1347. 
20 Wang, H.; Kong, D.; Johanes, P.; Cha, J. J.; Zheng, G.; Yan, K.; LiU, N.; Cui, Y. MoSe 2 and $\mathrm{WSe}_{2}$ Nanofilms with Vertically Aligned Molecular Layers on Curved and Rough Surfaces. Nano Lett. 2013, 13, 3426-3433.

21 Jung, Y.; Shen, J.; Liu, Y.; Woods, J. M.; Sun, Y.; Cha, J. J. Metal Seed Layer Thickness-Induced Transition from Vertical to Horizontal Growth of $\mathrm{MoS}_{2}$ and $\mathrm{WS}_{2}$. Nano Lett. 2014, 14, 6842-6849.

22 Wang, H.; Tsai, C.; Kong, D.; Chan, K.; Abild-Pedersen, F.; Nørskov, J. K.; Cui, Y. Transition-Metal Doped Edge Sites in Vertically Aligned $\mathrm{MoS}_{2}$ Catalysts for Enhanced Hydrogen Evolution. Nano Res. 2015, 8, 566-575.

23 Fei, L.; Lei, S.; Zhang, W.-B.; Lu, W.; Lin, Z.; Lam, C. H.; Chai, Y.; Wang, Y. Direct TEM Observations of Growth Mechanisms of Two-Dimensional $\mathrm{MoS}_{2}$ Flakes. Nat. Commun. 2016, 7, 12206.

24 Deng, Z. H.; Li, L.; Ding, W.; Xiong, K.; Wei, Z. D. Synthesized Ultrathin $\mathrm{MoS}_{2}$ Nanosheets Perpendicular to Graphene for Catalysis of Hydrogen Evolution Reaction. ChemComm 2015, 51, 1893-1896.

25 Lan, F.; Lai, Z:; Xu, Y.; Cheng, H.; Wang, Z.; Qi, C.; Chen, J.; Zhang, S. Synthesis of Vertically Standing $\mathrm{MoS}_{2}$ Triangles on SiC. Sci. Rep. 2016, 6, 31980.

26 Li, S.; Wang, S.; Salamone, M. M.; Robertson, A. W.; Nayak, S.; Kim, H.; Tsang, S. C. E.; Pasta, M.; Warner, J. H. Edge-Enriched 2D $\mathrm{MoS}_{2}$ Thin Films Grown by Chemical Vapor Deposition for Enhanced Catalytic Performance. ACS Catal. 2017, 7, 877-886.

27 Arrouvel, C.; Breysse, M.; Toulhoat, H.; Raybaud, P. A Density Functional Theory Comparison of Anatase $\left(\mathrm{TiO}_{2}\right)$ - and $\gamma-\mathrm{Al}_{2} \mathrm{O}_{3}$-Supported $\mathrm{MoS}_{2}$ Catalysts. J. Catal. 2005, 232, 161-178.

28 Costa, D.; Arrouvel, C.; Breysse, M.; Toulhoat, H.; Raybaud, P. Edge Wetting Effects of $\gamma-\mathrm{Al}_{2} \mathrm{O}_{3}$ and Anatase-TiO $\mathrm{T}_{2}$ Supports by $\mathrm{MoS}_{2}$ and CoMoS Active Phases: A DFT Study. J. Catal. 2007, 246, 325-343.

29 Helveg, S. An Industrial Perspective of the Impact of Haldor Topsøe on (In Situ) Electron Microscopy in Catalysis. J. Catal. 2015, 328, 102-110.

30 Tao, F.; Crozier, P. A. Atomic-Scale Observations of Catalyst Structures under Reaction Conditions and during Catalysis. Chem. Rev. 2016, 116, 3487-3539. 
31 Ross, F. M. Opportunities and Challenges in Liquid Cell Electron Microscopy. Science 2015, 350, aaa9886.

32 Feldman, Y.; Wasserman, E.; Srolovitz, D. J.; Tenne, R. High-Rate, Gas-Phase Growth of $\mathrm{MoS}_{2}$ Nested Inorganic Fullerenes and Nanotubes. Science 1995, 267, 222-225.

33 Feldman, Y.; Frey, G. L.; Homyonfer, M.; Lyakhovitskaya, V.; Margulis, L.; Cohen, H.; Hodes, G.; Hutchison, J. L.; Tenne, R. Bulk Synthesis of Inorganic Fullerene-Like MS2 $(\mathrm{M}=\mathrm{Mo}, \mathrm{W})$ from the Respective Trioxides and the Reaction Mechanism. J. Am. Chem. Soc. 1996, 118, 5362-5367.

34 Brandt, B. G.; Skapski, A. C. A Refinement of the Crystal Structure of Molybdenum Dioxide. Acta Chem. Scand. 1967, 21, 661-672.

35 Wienold, J.; Jentoft, R. E.; Ressler, T. Structural Investigation of the Thermal Decomposition of Ammonium Heptamolybdate by In Situ XAFS and XRD. Eur. J. Inorg. Chem. 2003, 2003, 1058-1071.

36 Stockmann, R. M.; Zandbergen, H. V.; Langeveld, A. D. v.; Moulijn, J. A. Investigation of $\mathrm{MoS}_{2}$ on $\gamma-\mathrm{Al}_{2} \mathrm{O}_{3}$ by HREM with Atomic Resolution. J. Mol. Catal. A: Chem. 1995, $102,147-161$.

37 Hansen, L. P.; Johnson, E.; Brorson, M.; Helveg, S. Growth Mechanism for Single- and Multi-Layer $\mathrm{MoS}_{2}$ Nanocrystals. J. Phys. Chem. C 2014, 118, 22768-22773.

38 Margulis, L.; Salitra, G.; Tenne, R.; Talianker, M. Nested Fullerene-Like Structures. Nature 1993, 365, 113-114.

39 Shannon, R. D.; Rossi, R. C. Definition of Topotaxy. Nature 1964, 202, 1000-1001.

40 Muijsers, J. C.; Weber, T.; Vanhardeveld, R. M.; Zandbergen, H. W.; Niemantsverdriet, J. W. Sulfidation Study of Molybdenum Oxide Using $\mathrm{MoO}_{3} / \mathrm{SiO}_{2} / \mathrm{Si}(100)$ Model Catalysts and Mo- ${ }^{\mathrm{IV}}{ }_{3-S u l f u r}$ Cluster Compounds. J. Catal. 1995, 157, 698-705.

41 Weber, T.; Muijsers, J. C.; van Wolput, J. H. M. C. ; Verhagen, C. P. J.; Niemantsverdriet, J. W. Basic Reaction Steps in the Sulfidation of Crystalline $\mathrm{MoO}_{3}$ to $\mathrm{MoS}_{2}$, As Studied by X-ray Photoelectron and Infrared Emission Spectroscopy. J. Phys. Chem. 1996, 100, 14144-14150.

42 Tauster, S. J.; Pecoraro, T. A.; Chianelli, R. R. Structure and Properties of Molybdenum Sulfide: Correlation of $\mathrm{O}_{2}$ Chemisorption with Hydrodesulfurization Activity, J. Catal. 1980, 63, 515-519. 
43 Shi, Q.; Li, Y.; Zhou, Y.; Miao, S.; Ta, N.; Zhan, E.; Liu, J.; Shen, W. The Shape Effect of $\mathrm{TiO}_{2}$ in $\mathrm{Vox} / \mathrm{TiO}_{2}$ Catalysts for Selective Reduction of $\mathrm{NO}$ by $\mathrm{NH}_{3}$. J. Mater. Chem. A 2015, 27, 14409-14415.

44 Picher, M.; Mazzucco, S.; Blankenship, S.; Sharma, R. Vibrational and Optical Spectroscopies Integrated with Environmental Transmission Electron Microscopy. Ultramicroscopy 2015, 150, 10-15.

45 Mele, L.; Konings, S.; Dona, P.; Evertz, F.; Mitterbauer, C.; Faber, P.; Schampers, R.; Jinschek, J. R. MEMS-Based Heating Holder for the Direct Imaging of Simultaneous In Situ Heating and Biasing Experiments in Scanning/Transmission Electron Microscopes. Microsc. Res. Tech. 2016, 79, 239-250.

46 Hansen, P. L.; Helveg, S.; Datye, A. K. Atomic-Scale Imaging of Supported Metal Nanocluster Catalysts in the Working State. Adv. Catal. 2006, 50, 77-95.

47 Allard, L. F.; Bigelow, W. C.; Jose-Yacaman, M.; Nackashi, D. P.; Damiano, J.; Mick, S. E. New MEMS-Based System for Ultra-High-Resolution Imaging at Elevated Temperatures. Microsc. Res. Tech. 2009, 79, 208-215.

48 Helveg, S.; Kisielowski, C. F.; Jinschek, J. R.; Specht, P.; Yuan, G:; Frei, H. Observing Gas-Catalyst Dynamics at Atomic Resolution and Single-Atom Sensitivity. Micron 2015, 68, 176-185.

49 Kilaas, R. Total Resolution LLC: Software for High Resolution Electron Microscopy, $<\mathrm{http}$ ://www.totalresolution.com $>$ (2016).

50 Mortensen, J. J.; Hansen, L. B.; Jacobsen, K. W. Real-Space Grid Implementation of the Projector Augmented Wave Method. Phys. Rev. B 2005, 71, 035109.

51 Enkovaara, J.; Rostgaard, C; Mortensen, J. J.; Chen, J.; Dulak, M.; Ferrighi, L.; Gavnholt, J; Glinsvad, C; Haikola, V.; Hansen, H. A. et al. Electronic Structure Calculations with GPAW: A Real-Space Implementation of the Projector Augmented-Wave Method. J. Phys.: Condens. Matter 2010, 22, 253202.

52 Bahn, S. R.; Jacobsen, K. W. An Object-Oriented Scripting Interface to a Legacy Electronic Structure Code. Comput. Sci. Eng. 2002, 4, 56-66.

53 Chase, M. W. NIST-JANAF Thermochemical Tables. 4 edn, (American Chemical Society, 1998). 
Figure 1. Surface sulfidation of $\mathrm{MoO}_{2}$ nanocrystals. a An illustration of a $\mathrm{MoO}_{2}$ nanocrystal before and after partial sulfidation by heating in $\mathrm{H}_{2} \mathrm{~S} / \mathrm{H}_{2}$. In the sulfided state, a partial coverage of co-existing $e-\mathrm{MoS}_{2}$ and $p-\mathrm{MoS}_{2}$ phases is illustrated by the $\mathrm{MoS}_{2}$ sheets (yellow) orientated perpendicular to and along the $\mathrm{MoO}_{2}$ crystal facets (blue), respectively. b, c TEM images of $\mathrm{MoO}_{2}$ nanocrystals after exposure to $10 \% \mathrm{H}_{2} \mathrm{~S}$ in $\mathrm{H}_{2}$ in situ at (b) $250^{\circ} \mathrm{C}$ for 300 min and (c) $300^{\circ} \mathrm{C}$ for $240 \mathrm{~min}$. The images are acquired in the microscope base vacuum $\left(5^{*} 10^{-6} \mathrm{mbar}\right)$ at $120^{\circ} \mathrm{C}$. A distinct lattice constant with the $\mathrm{MoS}_{2}$ (002) lattice spacing of $0.62 \mathrm{~nm}$ and the $\mathrm{MoS}_{2}$ (100) lattice spacing of $0.27 \mathrm{~nm}$ are resolved at the surface of the $\mathrm{MoO}_{2}$ nanocrystals in $\mathrm{b}$ and $\mathrm{c}$. Crystal lattice planes with spacing corresponding to $\mathrm{MoO}_{2}$ are resolved in the bulk of the nanoparticles.

Figure 2. Time-resolved TEM imaging of a $\mathrm{MoO}_{2}$ nanocrystal in situ during sulfidation. a-f Time-resolved TEM of a $\mathrm{MoO}_{2}$ nanocrystal during the exposure to 1 mbar of $10 \% \mathrm{H}_{2} \mathrm{~S}$ in $\mathrm{H}_{2}$ at $250^{\circ} \mathrm{C}$. The images are extracted from Video S1 in the Supporting Information at times [and accumulated electron dose] of (a) $45 \min \left[9 \times 10^{3} \mathrm{e}^{-} / \AA^{2}\right]$, (b) $65 \min \left[27 \times 10^{3} \mathrm{e}^{-} / \AA^{2}\right]$, (c) $85 \min$ $\left[45 \times 10^{3} \mathrm{e}^{-/ \AA^{2}}\right]$, (d) $160 \min \left[81 \times 10^{3} \mathrm{e}^{-/} / \AA^{2}\right]$, (e) $220 \min \left[126 \times 10^{3} \mathrm{e}^{-/} \AA^{2}\right]$ and (f) $280 \min$ $\left[153 \times 10^{3} \mathrm{e}^{-/} \AA^{2}\right]$. The time of 0 min corresponds to the time of gas introduction in the experiment. The inserts show Fast Fourier Transforms of the corresponding images. The open arrowhead indicates the location of $e-\mathrm{MoS}_{2}$. First the $\mathrm{MoO}_{2}$ (01-1) and later the (20-2) lattice planes are visible in the $\mathrm{MoO}_{2}$ bulk due to slight rotation of the nanocrystal with time. All TEM images have the same size. 
Figure 3. Interface between $e-\mathrm{MoS}_{2}$ and $\mathrm{MoO}_{2}$. a Close-up high resolution TEM image of the nanocrystal in Figure 2, acquired post mortem after sulfidation for 300 min exposure to 1 mbar $10 \% \mathrm{H}_{2} \mathrm{~S}$ in $\mathrm{H}_{2}$ at $250^{\circ} \mathrm{C}$. The superimposed crystal lattice vectors and zone axis (Z.A.) correspond to $\mathrm{MoO}_{2}$. b FFT image revealing the $\mathrm{MoO}_{2}(20-2), \mathrm{MoO}_{2}$ (11-1) and $\mathrm{MoS}_{2}(002)$ lattice planes, corresponding to a zone axis (Z.A.) view of the $\mathrm{MoO}_{2}$ nanocrystal in the [101] direction. c Image intensity line-scans in $\mathrm{MoO}_{2}$ and $e-\mathrm{MoS}_{2}$ obtained along $\mathrm{MoO}_{2}$ [20-2] and averaged over 10 pixels corresponding to the blue $\left(\mathrm{MoO}_{2}\right)$, orange $\left(e-\mathrm{MoS}_{2}\right)$ and yellow $(e$ $\mathrm{MoS}_{2}$ ) boxes in (a).

Figure 4. Atomic mechanism for topotaxy of $e-\mathrm{MoS}_{2}$ at the $\mathrm{MoO}_{2}(110)$ surface. a-d The topotactic transformation is illustrated by ball models of the atomic structures at an inclined projection (left) and by sketches of the [-11-1] oriented atomic rows with Mo in the center and the anionic content as the rim (right). The colors coding is dark blue for Mo in [-11-1] rows with the bulk density (full row), light blue for Mo in [-11-1] rows with half the bulk density (half row), red for $\mathrm{O}$ and yellow for $\mathrm{S}$. Crystal directions are quoted with reference to the $\mathrm{MoO}_{2}$ lattice. The atomic row numbering is equivalent in the ball models and sketches. All surface structures are obtained by DFT calculations. a Initial state for the sulfided $\mathrm{MoO}_{2}(110)$ surface (indicated by the dashed line). b The sulfided $\mathrm{MoO}_{2}(110)$ surface after displacement of row 1. c The sulfided $\mathrm{MoO}_{2}(110)$ surface in (b) after displacement of row 3 and surface O-S exchange of the exposed oxide surface in rows 2,4 and 5, resulting in a two-row $e-\mathrm{MoS}_{2}$ sheet. d The sulfided $\mathrm{MoO}_{2}(110)$ surface in (c) after displacement row 4 and 5 and O-S exchange in the 
exposed oxide surface, resulting in a four-row $e-\mathrm{MoS}_{2}$ sheet aligned with the $\mathrm{MoO}_{2}(20-2)$ planes.

e Calculated Gibbs free energies per unit cell for (a-d) for both the $\mathrm{MoO}_{2}(110)$ and (010) surfaces (Methods). 


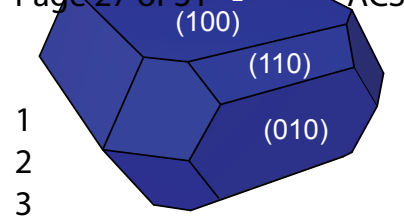

$b \longdiv { 4 }$

$54072 s^{(002)}$

$70.62 \mathrm{~nm}$

$0.62 \mathrm{~nm}$ 8 (0)2) 8 (0)2)

$10=0.9$ $0.24 \mathrm{rm}$ $11 . \quad \mathrm{MoO}_{2}(202)$ 2 nm 43

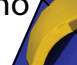
Ahano

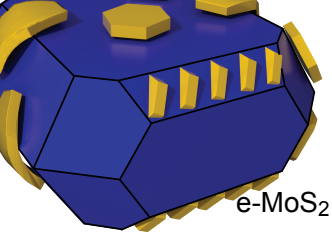

C 40 -

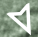

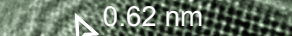

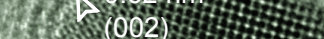

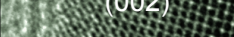

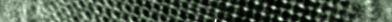

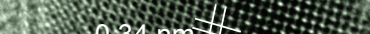
ex 0.84 nmotr.

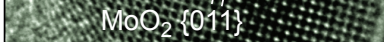

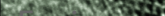

4 (n) $027 \mathrm{~nm}$

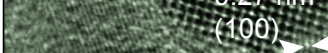

$2 \mathrm{~nm}$

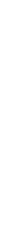




\section{Page 29 of 31}

\section{ACS Nano}

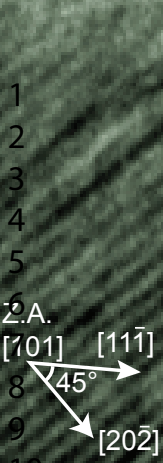

$\mathrm{b} \quad \mathrm{MoO}_{2}$

O(202)

$\mathrm{MoO}_{2}$

(111)

$\varangle_{(002)}^{\mathrm{MoS}_{2}}$

$\triangleright$

(1)

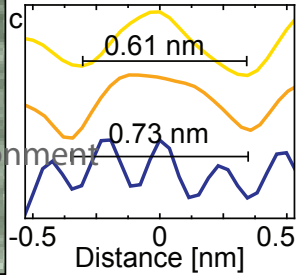



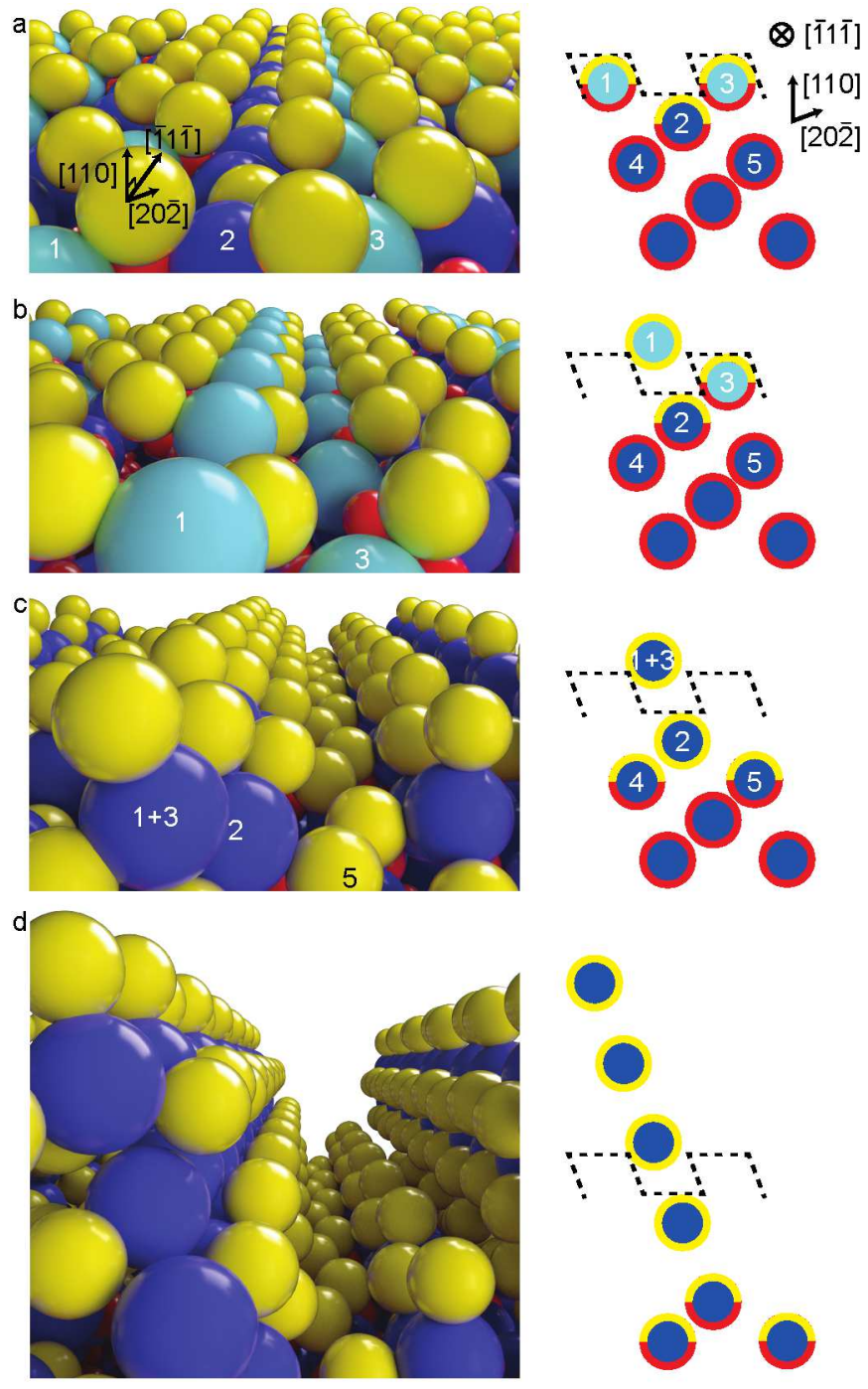

Mo, full row $\mathrm{Mo}$, half row $\mathrm{OS}$

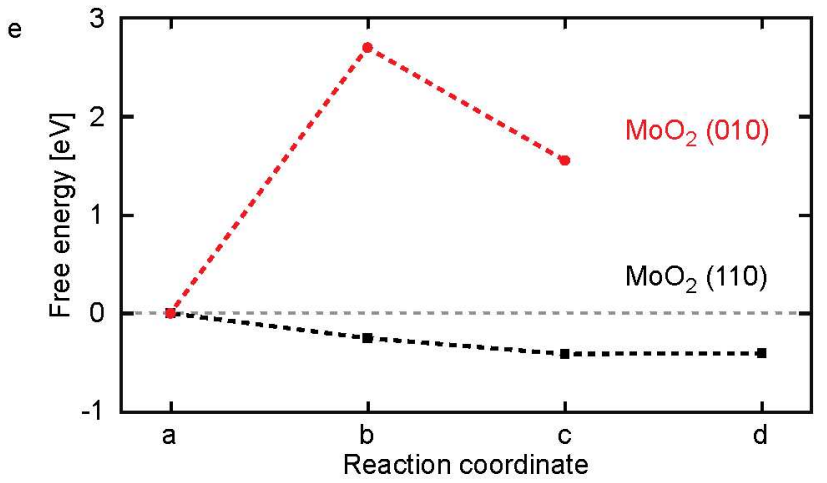

ACS Paragon Plus Environment 
$\mathrm{MoS}_{2}$

Page 31 of 31

ACS Nano

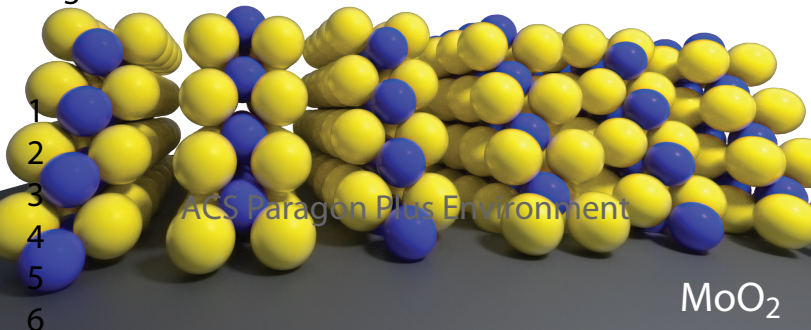

